\title{
Determination of foliar stage and number of leaves in maize when lower leaves are missing
}

\author{
JF Ledent *, D Mouraux \\ Centre de Recherches sur le Maïs (IRSIA), Laboratoire d'Ecologie des Grandes Cultures, \\ 2 place Croix du Sud - 1348 Louvain-la-Neuve, Belgium
}

(Received 14 February 1989; accepted 27 December 1989)

\begin{abstract}
Summary - Criteria allowing non-destructive determination of leaf rank throughout the season are presented. In the beginning, the first leaf and later on, the fifth leaf can be directly identified by length of lamina and height of collar (above soil level). When the fifth leaf disappears, determination of leaf rank is based on identification of the node where leaf 5 was inserted. Position (relative to soil level) of nodes 4, 5, 6 and relative length of the 5 lower aerial internodes allow identification. Observation of underground parts of the stem and roots, and more especially number and diameter of adventitious roots and position of nodes 4 and 5 relative to the stem tip allows further identification, but the method is destructive.
\end{abstract}

modelling / phyllochron / internodes / adventicious roots / phenological scale

Résumé - Détermination du stade foliaire et du nombre de feuilles chez le maïs quand les feuilles de base ont disparu. Des critères permettant la détermination du numéro d'ordre des feuilles, à travers la saison sont présentés. On reconnait la première feuille à l'extrémité arrondie de son limbe, et quand l'extrémité n'est plus clairement visible à cause de la senescence, on se base sur la longueur du limbe $(5 \mathrm{~cm}$ environ) et le niveau du col (zone ligulaire) par rapport au sol (moins de $2 \mathrm{~cm}$ ) (fig 1, tableau II). Quand la première feuille a disparu, on repère la cinquième feuille. Son col est situé à plus de $10 \mathrm{~cm}$ du sol (tableau II) alors que celui de la feuille suivante est situé entre $20 \mathrm{~cm}$ et $30 \mathrm{~cm}$ au-dessus du sol (dimensions définitives atteintes au stade 6 et 7 feuilles déployées, respectivement). Quand le limbe a disparu, on peut se référer au nœud 5 où la cinquième feuille s'insérait (par sa gaine foliaire) à la tige. Le nœud 5 est observable dès le stade 8 feuilles déployées. Il est situé au ras du sol ou juste au-dessus, toujours à moins de $2 \mathrm{~cm}$. On le distingue aisément du nœud 6 situé nettement plus haut (tableau III, fig 2). Si un doute existe quant à l'identification du ncud 5, confirmation peut être obtenue à partir de l'observation des longueurs $t_{n}$ des entrenœuds aériens de la base. Les cinq entrenœuds successifs situés au-dessus de n5 ont en effet des longueurs ( $\left.t_{n}\right)$ dont les rapports $r_{n}=t_{n} / t_{n-1}$ présentent une séquence typique. On a respectivement $r_{n}=2,5^{+}, 2^{-}, 1,5^{-}, 1$ pour les valeurs sucessives de $n$, (tableau III, fig 2). Cela signifie que le second entrenceud au-dessus du noud 5 est plus de 2.5 fois plus long que le précédent, que le troisième est un peu moins du double $(1,5$ à 2 fois) du second, etc... Cette observation n'est valable que quand la longueur de ces entrencuds s'est stabilisée, c'est-à-dire après le stade $12-13$ feuilles déployées. L'identification du nœud 5 peut également se faire de façon destructive en fin de saison (après la floraison) en déterrant la plante, coupant les racines adventives et dégageant la partie souterraine de la tige (fig 3). Celle-ci se présente sous la forme d'une pyramide circulaire inversée. Le nœud 5 est celui qui se trouve à 2,5 cm-3 $\mathrm{cm}$ de sa pointe, tandis que $n 4$ se trouve à environ $1,5 \mathrm{~cm}$ (tableau $\mathrm{IV}$, fig 3). L'observation de la base des racines adventives peut également apporter des informations, mais le diagnostic est moins sûr, vu la grande variabilité. Le premier noud avec plus de quatre racines, et avec de grosses racines (diamètre $\geq 4-5 \mathrm{~mm}$ ) est $n 4$ (tableau $\mathrm{V}$ ), mais ce n'est pas général. L'utilisation de plusieurs de ces critères à la fois permet une identification quasi sans erreur du numéro d'ordre des feuilles (tableau VI).

modélisation / phyllochrone / intrenœuds / racines adventives / échelle phénologique

\section{INTRODUCTION}

The number of leaves (foliar stage) is an important characteristic to define developmental stages in maize before silking. Phenological scales refer to either the number of leaves with their tip visible (Anonymous, 1981a,b; Gay, 1985) or more commonly to the number of fully expanded leaves (collar or ligule visible; Hanway, 1963, 1966, Schütte and Meier, 1981; Groot et al, 1986; Sibma, 1987; Ledent, 1988). In some cases (Delhaye, 1985) the reference is not so narrowly defined, the number of leaves referring apparently to leaves displaying an important

\footnotetext{
* Correspondence and reprints
} 
fraction of their full length. The relatively close relationship between rate of leaf emergence and accumulated temperature (Tollenaar et al, 1979; Kiniri and Ritchie, 1981; Bonhomme, 1984) makes foliar stage a key parameter in maize growth models (Stapper and Arkin, 1980; Jones and Kiniri 1986).

Foliar stages are related to major developmental events such as end of juvenile phase and independence from the seed (Kiniry et al, 1983a,b; Barloy, 1984) or male inflorescence initiation (Gay and Menetrier, 1978; Tollenaar and Hunter, 1983; Gay, 1984). Due to its relation with leaf area foliar stage it is also associated with photosynthetic assimilation.

An accurate determination of the developmental stage is useful for testing models, recording the timing of major events affecting crop growth (occurrence of damages, etc.) defining the moment of pesticide application, etc. A correct determination of foliar stage takes into account all leaves, including those which have already disappeared (through senescence, damage by wildgame, etc) at the base of the plant.

The objective of this work was to define criteria allowing an accurate determination of the rank of each leaf after complete disappearance of the first basal leaves.

\section{MATERIAL AND METHODS}

We define the rank of a leaf from its position in the succession of leaves, starting from the first leaf appearing after seedling emergence. Foliar stage is taken as the rank of the last (uppermost) leaf, with collar visible (on the abaxial side). Observation of the abaxial side of the leaf is preferred to observation of the ligule on the adaxial side since the exact timing of collar visibility is more clearly cut and easier to determine.

Observations were made over a period of 3 years, on a series of trials with different varieties, and different locations (table I). Markings with colour were made on leaves of given rank as soon as they appeared. Non-destructive observations were made through time on the same plants $(10-20$, according to trial and character measured): length of expanded lamina, height of collars and visible nodes (above soil level), number of leaves visible, number of brace roots. Observations on leaf emergence were made daily in Trials 1 and 3 .

Other plants were also harvested twice a week and dissected for measurement of length of non-visible parts: internodes, non-emerged leaves, observation of plant base below soil level, diameter and length of underground internodes, diameter and number of adventicious roots (Trial 3 ). In Trial 2 , observations of parts below soil level were made only on plants harvested at the end of the season.

Further details concerning the number of observations and trials are given in the table of results.

Node position above soil level is determined (nondestructively) by the position of an imaginary line passing through the middle of the locally swollen zone, observed in each internode just above the point of attachment of the leaf sheath. In the lower, mature internodes, this corresponds to the middle of the zone

Table I. Trials used: location and cropping techniques. $a=$ All trials are in large plots $(\geq 0.5 \mathrm{ha})$ whith the exception of $2^{2}$ $(7 \mathrm{~m} \times 3.2 \mathrm{~m})$ and $4(20 \mathrm{~m} \times 6.4 \mathrm{~m}) ; \mathrm{b}=$ Total number of leaves (number of observations $n=10$ in $\exp 2$, and 20 in $\exp$ $1,3)$; standard deviation varied from 0.4 to 0.8 according to the case).

\begin{tabular}{|c|c|c|c|c|c|c|c|}
\hline Experiment & Year & Location & Variety & $\begin{array}{l}\text { Sowing } \\
\text { date }\end{array}$ & $\begin{array}{c}\text { Density of sowing } \\
\text { (p1/ha) }\end{array}$ & $\begin{array}{l}\text { Nitrogen } \\
\text { (kg N/ha) }\end{array}$ & $\begin{array}{c}\text { Manure } \\
\text { (T/ha) }\end{array}$ \\
\hline $\begin{array}{l}1 \\
2\end{array}$ & $\begin{array}{l}1987 \\
1987\end{array}$ & $\begin{array}{l}\text { Louvain-la-Neuve } \\
\text { Corroy-le-Grand }\end{array}$ & Lixis $(16.2)^{b}$ & $18 / 4$ & 100,000 & 150 & 30 \\
\hline $2^{a}$ & & field 1 & $\begin{array}{l}\text { Gracia (18.4), } \\
\text { Tonus }(16.2)\end{array}$ & $1 / 5$ & 105,000 & 190 & 40 \\
\hline $2^{b}$ & & field 2 & $\begin{array}{l}\text { Brulac (14.8), } \\
\text { Brulouis (14.2) } \\
\text { Dea (15.7), Issa (14.4), } \\
\text { Sava (15.4), } \\
\text { Tonus (15.2), Trak (14.6) }\end{array}$ & $1 / 5$ & 90,000 & 190 & 40 \\
\hline 3 & 1988 & Louvain-la-Neuve & Lixis (15.8) & $26 / 4$ & 100,000 & 190 & 30 \\
\hline 4 & 1988 & Corroy-le-Grand & $\begin{array}{l}\text { Gracia, Tonus, } \\
\text { Brulouis, Dea, } \\
\text { Lixis }\end{array}$ & $\begin{array}{r}204 \\
7 / 5\end{array}$ & 94,000 & 116 & 40 \\
\hline 5 & 1988 & $\begin{array}{l}\text { 5-1 Cerfontaine } \\
\text { 5-2 Hives }\end{array}$ & $\begin{array}{l}\text { Lixis } \\
\text { Lixis }\end{array}$ & $\begin{array}{l}3 / 5 \\
9 / 5\end{array}$ & $\begin{array}{r}101,000 \\
93,000\end{array}$ & $\begin{array}{r}60 \\
150\end{array}$ & $\begin{array}{l}60 \\
40\end{array}$ \\
\hline 6 & 1989 & Louvain-la-Neuve & Lixis (15.2) & $1 / 5$ & 110,000 & 140 & 40 \\
\hline 7 & 1989 & Corroy-le-Grand & Dea, Gracia, Lixis & $10 / 5$ & 95,000 & 100 & 30 \\
\hline
\end{tabular}


of emission of the corresponding whorl of adventicious roots.

Measurements are made with a ruler. The lower side of the ruler (lower end, with zero mark) is placed on the soil, as close as possible to the plant basis, avoiding as for as possible local irregularities such as gullies, clods, stones, ... Thus, the ruler is placed each time on a spot estimated visually as representing the average soil level within the row, near the plant base.

The length of internode is the distance between 2 successive nodes. This is the difference between positions (as defined above) of 2 successive nodes.

For higher internodes, when the nodes are fully visible, being totally emerged from the sheath(s) attaching to the preceding, lower node(s), length of internode may also be defined as the distance between the points of attachment of 2 successive leaf sheaths. If the zone of attachment is hidden by lower sheaths (case of lower internodes or measurements early in the season) this latter method requires plant dissection (destructive). Both methods give practically the same estimation of internode length (the distance between sheath insertion and swelling differ little for the 2 successive nodes).

\section{RESULTS}

\section{Determining if leaf one is missing}

As long as leaf 1 can be observed directly, determination of leaf rank is relatively simple. Therefore the first step in determination of leaf stage should be examining whether leaf 1 is missing or not. When lower leaves are senescent, precise criteria are needed to answer this question. To define such criteria, typical features of the first leaf were observed when the leaf was still green. Only the features recognizable when the leaf was senescent were considered afterwards.
The first leaf to appear on a young maize seedling is typical through its rounded tip and its small length (fig 1). In all cases observed (table II) its lamina displayed a length of about $5 \mathrm{~cm}$, which was half the length of the second leaf lamina. Such a ratio between the length of 2 subsequent leaves is only observed for leaf 2 and 1 (table II) and may therefore be used as a criterion for determining if leaf 1 is still present or not or if the lowermost leaf is really leaf 1 . Height of insertion is another useful criterion: the collar of the first leaf is less than $2 \mathrm{~cm}$ above soil level whereas the second leaf collar is twice as high (table II).

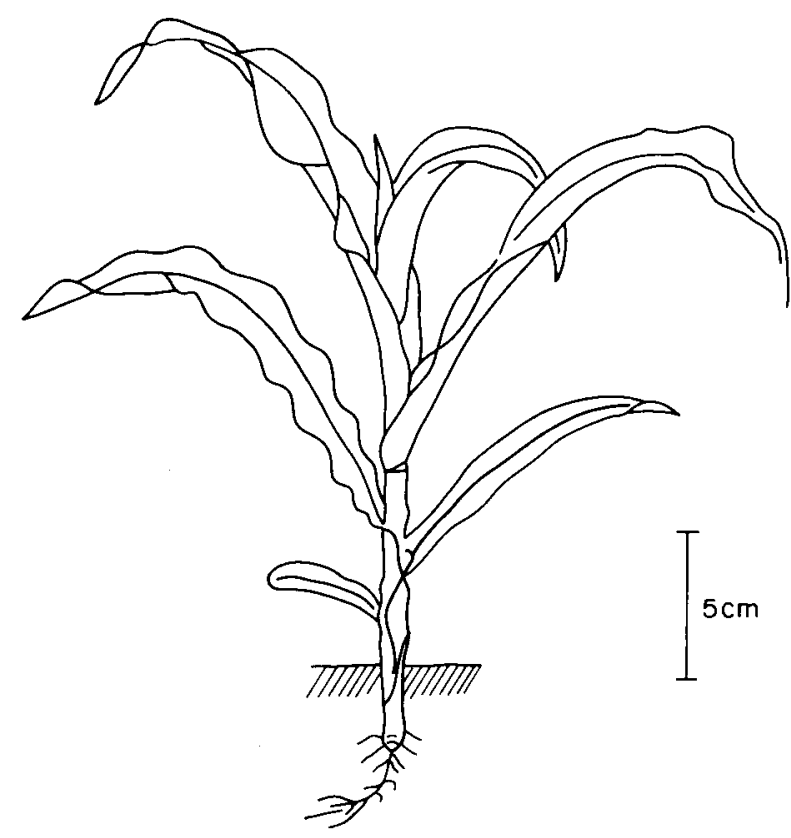

Fig 1. Plant dimensions at foliar stage 4 (collar of fourth leaf visible): observe height of collar of first leaf, and length of laminae.

Table II. Identification of leaf 1 and 5 through lamina length and height of collar.

(a) experiment number, see table l; number of observation (1) $n=25$, (2) $n=25$, (3) $n=25$, (4) $n=20$, (6) $n=20$, (7) $n=20$; (b) mean $X$; (c) standard deviation, $s$; (d) symbols: $l_{1}, l_{2}$ : length of lamina (cm) of leaf $1,2, \ldots ; h_{c 1}, h_{c 2}$, etc: height $(\mathrm{cm})$ above soil level of collar of leaf $1,2, \ldots:(e)$ Other values of $I_{2} / l_{1}$ for Lixis: $X=2.0(s=0.19)$, exp $5-1, n=10$.

\begin{tabular}{|c|c|c|c|c|c|c|c|c|c|c|}
\hline & \multicolumn{3}{|c|}{ Lixis } & \multirow[b]{2}{*}{$1989(6)$} & \multirow[b]{2}{*}{$1989(7)$} & \multicolumn{2}{|c|}{ Tonus } & \multicolumn{2}{|c|}{ Gracia } & \multirow[b]{2}{*}{$1989(7)$} \\
\hline & 19871 & & $1988(3)$ & & & $1987(2)$ & 1988(4) & $1987(2)$ & 1988(4) & \\
\hline$\left.\right|_{1} ^{\text {(d) }}$ & $4.6^{\text {(b) }}$ & $(0.52)^{(\mathrm{c})}$ & $4.6(0.85)$ & - & - & $5.2(0.48)$ & $5.2(0.50)$ & $5.6(0.50)$ & $5.7(0.69)$ & - \\
\hline$l_{2} /\left.\right|_{1}{ }^{(e)}$ & 1.7 & $(0.20)$ & $2.2(0.32)$ & - & - & $2.0(0.16)$ & $1.9(0.08)$ & $2.1(0.14)$ & $1.8(0.10)$ & - \\
\hline$h_{\mathrm{c} 1}$ & - & - & $1.7(0.34)$ & - & - & $-\quad-$ & $1.5(0.18)$ & $-\quad-$ & $1.9(0.44)$ & - \\
\hline$h_{\mathrm{c} 2}$ & - & - & $3.4(0.41)$ & - & - & - & $3.4(0.31)$ & - & $4.0(0.50)$ & - \\
\hline$h_{c 4}$ & - & - & $7.9(0.97)$ & $10.0(1.49)$ & $5.9(0.86)$ & $6.6(1.00)$ & $8.3(0.62)$ & $7.6(0.57)$ & $8.6(1.04)$ & - \\
\hline$h_{c 5}$ & - & - & $12.8(1.92)$ & $13.8(1.61)$ & $10.6(1.59)$ & $9.8(1.25)$ & $12.0(0.93)$ & $11.6(1.01)$ & $13.0(1.34)$ & $12.6(2.01)$ \\
\hline$h_{c 6}$ & - & - & $18.1(2.50)$ & $22.2(3.44)$ & 17.6 (2.54) & $14.9(2.14)$ & $18.1(1.54)$ & $17.3(1.62)$ & $20.4(2.61)$ & $22.5(4.60)$ \\
\hline
\end{tabular}


Senescence of the first leaves became significant at foliar stage 5-6, but observation of lamina length is still possible when the leaf, completely senesced lies dead on the soil, still attached to the plant by remnants of its leaf sheath. Observation of rounded tip is difficult at that stage. At foliar stage 11 (mid July) all lower 3 or 4 leaves had completely senesced $(\exp 3)$ and remnants of first leaves were no longer identifiable. Senescence is likely to vary with environmental conditions, stress, etc... but our observations correspond to those of Hanway (1963) who noted death of 2 and 4 lowermost leaves at foliar stages 8 and 12, respectively. In figures presented by Sibma (1987) the first 3 leaves senesced at stages 8,10 and 12 respectively.

\section{Determination of leaf 5}

When the lowermost leaf still present on the plant does not correspond to the criteria presented above it is not a first leaf; the first leaf has disappeared and can no longer be used as a reference. Leaf 5 can be used as a new reference for counting leaves and determining their rank. The node where the sheath of leaf 5 attaches to the stem is indeed situated at or very close above soil level (see below). This node may be identified at first by the presence of localized swelling around the circumference of the stem. It becomes detectable with the fingers at foliar stage 8 (exp 3) ie end June in our conditions. Later on, adventicious roots develop from the swollen zone (see below).

The advantage of node identification is that a node remains observable when the leaf has completely senesced. Before its senescence, leaf 5 can also be identified by the height of its collar. It is the lower leaf with a collar at an average height of about $>10 \mathrm{~cm} \pm 0.5$ above soil level or larger (table II). The collar height of the following leaf (leaf 6) is double the height of the collar of leaf 5 , at about $20 \mathrm{~cm}$ on average. In the warmer and dryer conditions of 1989 (exp 6, sandy soil; table II) the height of the collar of leaf 5 to 6 tends to be higher. Even under those conditions leaf 5 is the first leaf to have its collar significantly above $10 \mathrm{~cm}$ and leaf 6 has its collar at about 20 $\mathrm{cm}$ and always below $30 \mathrm{~cm}$. This higher position of leaf collars was not observed in $\exp 7$, the same year on better soils (loam).

Observations of collar height apply only when the collar has reached its maximum height. Daily measurements in exp 3 (data not presented) showed that the collar of leaf $n$ had reached $90 \%$ of its final height towards the end of foliar stage $n$ (just before emergence of the collar of leaf $n+1)$ if $n=6$. For leaf $7-9$, final height was reached in the middle of stage $n+1$, and for leaf 10 at the end of stage $n+1$.

When criteria for identifying leaf 5 become applicable, first leaves are still identifiable on a large proportion of plants. This allows continuity and a possibility of cross checking to determine leaf rank.

\section{Observations of lower aerial nodes, after foliar stage 8-10}

A node on the stem corresponds to the zone of insertion of a leaf sheath. In the beginning, nodes are not visible and are not observable nondestructively. Nodes become successfully observable during stem elongation. A whorl of adventicious roots (brace roots, crown roots) develops just above each of the lower nodes in a part of the stem with a larger diameter (swelling, around the circumference) (fig 2 and 3 ). Localized swelling (bulge) and emergence of the root facilitates the detection of nodes. For practicability, we redefine node $n$ as the zone of insertion of leaf sheath $n$, plus the bulge just above it. In the case of lower nodes, the swelled zone bears a whorl of adventicious roots. Thus the adventicious roots of node $n$ when emerged pierce the base of the leaf sheath $n$.

The advantage of the use of nodes is that they remain observable when the leaves attached to them have disappeared. Due to their typical position relative to soil level, nodes 5 and 6 are

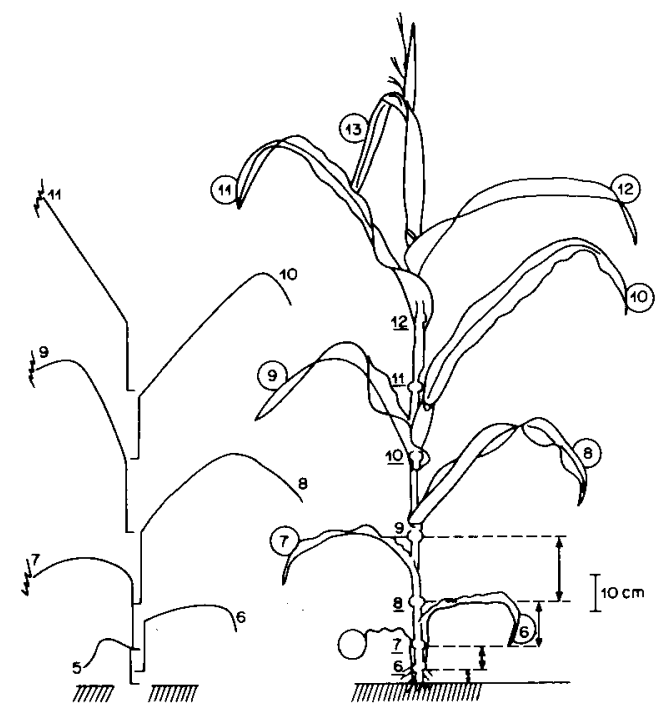

Fig 2. Schematical presentation of a maize plant at foliar stage 13. Identification of leaves (number within circle) and corresponding node (number underlined) is given (right). Diameter of nodes is not represented on scale. Note the relative heights of 4 lower aerial internodes (arrows). Diagram on the left shows the connections between corresponding nodes, sheaths and lamina. 


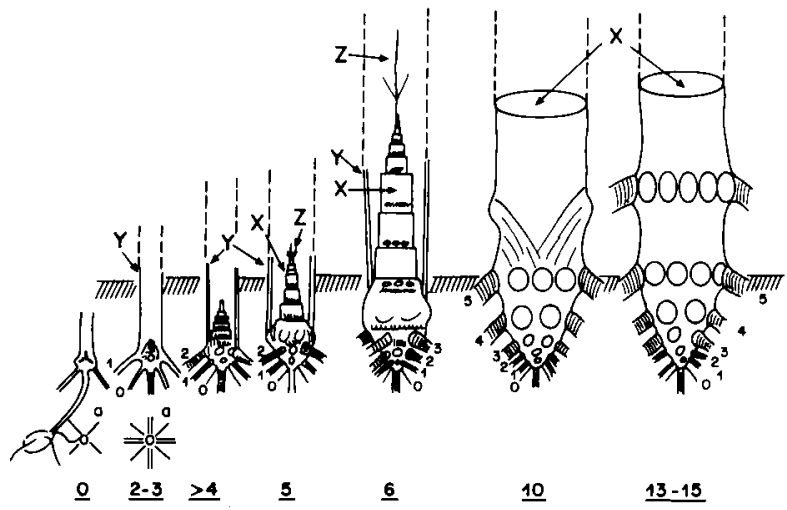

Fig 3. Schematic view of lower part of stem (cv Lixis; underground parts included). Nodes are identified by number: ( 0 is coleoptilar node). Adventicious roots are represented only by their base. Underlined numbers are foliar stages; $X$ : true stem (visible only after dissection), Y: pseudostem, Z: panicle, a: view of stem tip from beneath with roots corresponding to node 0 and 1.

important for determination of leaf ranking (fig 2 and 3). Node 5 (where the sheath of leaf 5 attaches to the stem) is situated at or just above soil level $( \pm 1 \mathrm{~cm})$ in most cases (visual estimation in all experiments except exp 4 and 6). In exp 4 actual measurements gave values of $0.7(s=0.41), 1.1(s=0.22), 1.0(s=0.38) \mathrm{cm}$ above soil level for the height of node 5 of Tonus, Gracia and Lixis respectively. In exp 6 (Lixis) node 5 was $1.1 \mathrm{~cm}( \pm 0.6 \mathrm{~cm}, n=72)$ above soil level. Node 6 is always clearly above soil level (mostly between 2 and $4 \mathrm{~cm}$ above soil, selection of results in table III). Complementary information is, that observation on 100 plants and 14 varieties showed that node 4 remains below soil level in $82 \%$ of cases (exp 2 ) whereas node 7 was situated $5-10 \mathrm{~cm}$, above soil level according to cultivars $[X=7.7 \mathrm{~cm}$ exp 2; and $X=10.9 \exp 3(s=3.71)]$.

Under warm conditions such as in phytotron (data not presented) or in the warm conditions of $\exp 6$ the length of lower internode is higher (exp 6 ; table III). Even in the case of exp 6, node 5 was the first aerial node, it was situated close to soil level (at $1.1 \pm 0.6 \mathrm{~cm}, n=72$ ) and its height was never above $2 \mathrm{~cm}$.

Measurements were made with a ruler, graduated in $\mathrm{mm}$. Although theoretically an accuracy of 1-2 $\mathrm{mm}$ is possible, small irregularities of soil level increase the variability of measurement. Errors of up to $5 \mathrm{~mm}$ on individual measurements are likely. Little attention should therefore be given to the decimals appearing in the tables. This error is too small however to affect identification of leaf rank. Observation of nodes 5 and 6 provides a simple criterion for identifying the rank of all aerial nodes and leaves. The criterion may only be used when the stem part below nodes 5 and 6 has terminated most of its elongation ie after foliar stage 8-10 (end June, early July, in our conditions). Fortunately this corresponds to the time when these nodes can be easily observed non-destructively through the local swelling.

Since node 4 is situated only a small depth below soil level (about 4-5 mm) it may sometimes be confused with node 5 . Presence of small gullies, or ridges near plant bases may indeed affect the position of node 4 relative to

Table III. Identification of lower aerial nodes.

(a) $h_{n}$ is height in $\mathrm{cm}$ (above the soil level) of node $n$. Standard deviation is between parentheses; $(b) r_{n}=t_{n} / t_{n-1}$ where $t n$ is the length of the stem internode situated between nodes $n$ and $n-1$. Standard deviation is given between parentheses; (c) number of observations.

(a)

Height of sixth node $h_{n 6}$ (b)

Relative length $r_{n}$ of internodes
${ }_{n}(\mathrm{c})$
$\exp$
$r_{7}$
$r_{8}$
$r_{9}$
$r_{10}$

\begin{tabular}{|c|c|c|c|c|c|c|c|c|c|c|c|c|}
\hline Brulac & 1.9 & $(0.72)$ & 10 & 2 & 3.2 & $(0.91)$ & 2.2 & $(0.44)$ & 1.4 & $(0.21)$ & 1.2 & $(0.17)$ \\
\hline Brulouis & 2.5 & (1.22) & 8 & 2 & 2.8 & $(0.41)$ & 2.0 & $(0.52)$ & 1.4 & $(0.12)$ & 1.2 & $(0.16)$ \\
\hline Dea & 1.3 & $(0.41)$ & 10 & 2 & 5.4 & $(1.15)$ & 1.9 & $(0.44)$ & 1.2 & $(0.14)$ & 1.2 & (0.69) \\
\hline & 3.5 & (1.77) & 20 & 7 & 3.1 & $(1.07)$ & 1.6 & $(0.43)$ & 1.3 & $(0.19)$ & 1.1 & $(0.10)$ \\
\hline Issa & 4.4 & (1.29) & 9 & 2 & 2.3 & $(0.69)$ & 1.7 & $(0.19)$ & 1.5 & $(0.17)$ & 1.3 & $(0.06)$ \\
\hline Sava & 2.9 & (1.54) & 10 & 2 & 2.8 & (1.12) & 1.6 & $(0.47)$ & 1.4 & $(0.20)$ & 1.1 & $(0.15)$ \\
\hline Tonus & 2.2 & $(0.86)$ & 8 & 2 & 3.1 & $(0.70)$ & 1.8 & (0.34) & 1.4 & $(0.13)$ & 1.1 & $(0.10)$ \\
\hline Trak & 3.5 & $(1.20)$ & 10 & 2 & 2.5 & $(0.39)$ & 1.7 & $(0.27)$ & 1.3 & $(0.14)$ & 1.1 & $(0.05)$ \\
\hline Lixis & 4.0 & $(0.97)$ & 20 & 1 & 2.8 & $(0.51)$ & 1.7 & $(0.26)$ & 1.3 & $(0.17)$ & 1.1 & $(0.13)$ \\
\hline & 3.5 & (1.51) & 20 & 3 & 2.3 & $(0.63)$ & 1.9 & $(0.50)$ & 1.4 & $(0.16)$ & 1.1 & $(0.11)$ \\
\hline & 5.8 & (2.05) & 72 & 6 & 2.5 & $(0.47)$ & 1.6 & $(0.22)$ & 1.3 & $(0.15)$ & 1.1 & $(0.09)$ \\
\hline & 3.4 & $(1.58)$ & 20 & 7 & 2.9 & $(0.80)$ & 1.8 & $(0.36)$ & 1.4 & $(0.15)$ & 1.2 & $(0.08)$ \\
\hline Gracia & 4.7 & $(1.28)$ & 20 & 7 & 2.1 & $(0.48)$ & 1.5 & $(0.15)$ & 1.3 & $(0.11)$ & 1.2 & $(0.11)$ \\
\hline
\end{tabular}


soil level. Observations of positions of subsequent nodes (6 and 7 ) are then useful. Observations of number and diameter of adventicious roots or stem internode diameter may also be used to discriminate (see below description of lower part of stem).

\section{Sequence of internode lengths}

Once the stem is fully elongated, or at least when the stem parts below node 10 have terminated most of their elongation (fig 2) another criterion may also be used to determine leaf or node ranks. Daily observations (exp 3 , data not presented) showed that stem parts below node 10 had terminated most $(90 \%)$ of their elongation between foliar stages 12-13. From that moment on, final lengths of aerial internodes below node 10 can be measured or estimated visually. Defining $t_{n}$ as the internode (length) between node $n$ and $n-1$, the final length of the first aerial internode is $t 6$.

Lengths of internodes vary with cultivar and environmental conditions, but the ratios $r_{n}=t_{n} / t_{n-1}$ show a typical pattern (table III, fig 2). The values vary from 5.5 to 1 but after rounding off, values of $2^{+}, 2^{-}, 1.5^{-}, 1$ (respectively) are found for $r_{n}$ with $n$ varying from 7 to 10 (respectively). This means that the second internode above soil level $\left(\mathrm{t}_{7}\right)$ is more than twice $\left(2^{+}\right.$or $2.5^{+}$times) as long as the first one $\left(\mathrm{t}_{6}\right)$; in some cases this may be as high as 5 times; the third internode $\left(t_{8}\right)$ is less than twice $\left(2^{-}\right)$as long as the second $\left(t_{7}\right)$ etc and above node 9 , lengths of fully elongated internodes vary little from 1 internode to the next $\left(2^{-}\right.$means generally between 1.5 and $2,1.5^{-}$between 1.5 and 1.3 , and 1 smaller then 1.3).

Thus, ratios $r_{n}$ can be estimated visually and used as a criterion to identify node 5: the 5 aerial internodes above node 5 must present the pattern $2.5^{+}$(or $2^{+}$), $2^{-}, 1.5^{-}, 1$ for $r_{n}(n=7-10)$. The ratio $r_{6}$ measured on harvested plants (uprooted) was $2.3(s=0.49, n=19$, exp 1). In $\exp 2$, node 4 was very close to soil level and could be observed without uprooting in 30 out of 113 plants of numerous varieties; the mean value of $r_{6}$ was 3.6. Thus in this case node 4 was close to soil level and lengths of internodes were estimated inadvertendly from the internodes above node 4 the following pattern was observed: $2^{+}, 2^{+}, 2^{-}, 1.5,1$ for $r_{n}(n=6-10)$. Therefore discrimination between node 4 and 5 is possible.

The sequence of internode lengths at the plant basis (aerial internodes) in field conditions, seems to have some generality. It is not in- consistent with internode descriptions by Hanway (1966). Moreover, rapid visual estimations made occasionally during visits of field trials or farmers fields in neighbouring countries appear to be generally consistent with our conclusion. Since these observations were not systematically conducted and recorded, they have not been presented.

When the stem is fully elongated (after silking) visual estimations of internode lengths may also be done from the higher internodes to the lower ones. According to the above observations, the lowest internode, with a length differing little from the length of the internode above it, should be the internode just above node 9 . Since it is not always easy to discriminate between $r_{n}=1$ (1.2$0.8)$ and $r_{n}=1.5^{-}(1.5-1.25)$ this second procedure is more subject to error.

To use these criteria based on $r_{n}$ it should be remembered that the final length (within $10 \%$ ) of an internode $t_{n}$ is reached 2-3 foliar stages after foliar stage $n$ (the delay increases with $n$; observations on 20 plants measured daily in $\exp 3$ ).

The criteria based on internode length applies to plants growing in the field. They do not apply to plants growing in pots, in the phytotron (data not presented).

\section{Observation of stem parts below soil level (destructive)}

The lower stem internodes elongate very little and remain below soil level (Hanway, 1966, Girardin et al, 1986). Nodes underground develop whorls of adventicious roots of the same nature as those visible on aerial nodes (Picard et al, 1985). Observations of underground parts are destructive. They require pulling the plant out of the ground, and washing its base. Cutting adventicious roots to a length of $\pm 1 \mathrm{~cm}$ is also required (otherwise the stem internodes are difficult to observe). Observations were made at 7 different dates on 5 plants/date (exp 3), twice after anthesis (exp 1) or once before final harvest (exp 2) to determine the quantitative characters of the stem basis. Observations were also done in $\exp 6$ on one date (at silking). The evolution of the stem basis is presented schematically in fig 3 . In the beginning, the stem is very short, and is completely hidden within the pseudostem formed by sheaths. Internodes develop and reach their full length and width one after the other. The pseudostem has the diameter of the last developed node. Diameters of successive nodes and internodes increase from one internode to the other giving the stem basis the 
typical shape of a circular pyramid, placed on its tip (upside down). When fully developed the underground pyramid is formed of 5 internodes situated between node zero (corresponding to the zone of attachment of the coleoptile) and node 5 , at soil level. Stem diameter is about $2 \mathrm{~cm}$ at the level of node 4 (fig 3).

The underground pyramid has a full length (height) of $2.5-3 \mathrm{~cm}$. The distance between tip of pyramid and node 5 is $2.5-3 \mathrm{~cm}$, whereas the distance between tip and node 4 is about $1.5 \mathrm{~cm}$ (fig 3 and table IV). In exp 7 observations (1 month after silking) of the position of node 5 and 4 relative to the shoot tip gave respectively (in $\mathrm{cm}$ ) $2.6 \pm 0.35$ and $1.4 \pm 0.11$ for Lixis $(n=18)$ (or 2.6 \pm 0.26 and $1.5 \pm 0.16$ for Gracia $(n=19)$ ). These dimensions can be used as criterion to discriminate between node 5 and 4 . Note that node position was determined by the position of an imaginary line passing through the middle of each zone of attachment of adventicious roots.

Internode $t_{5}$ (just below node 5 ) is the first internode (starting from stem base ie from tip of pyramid) with a length clearly higher than the diameters of the roots of corresponding node $\left(n_{5}\right)$. Node 4 and lower nodes as well as corresponding root whorls appear stacked on each other as observed by Picard et al, 1985 whereas between node 4 and 5 a smooth stem surface devoid of adventicious roots can be clearly observed in many cases.

\section{Observation of underground adventicious roots (destructive)}

As observed by Picard et al, 1985) there is a relationship between foliar stage and appearence of new whorls of adventicious roots (crown roots). In trial 3 (Fig 3) (table V) roots of whorl $n$ appeared through the sheath basis of leaf $n$, around foliar stage $n / 2$. It was not our objective to describe with great accuracy the development of the root system. Observations of root emergence were limited to samples of 2-3 plants only harvested each time average foliar stage had increased by 1 unit, approximately. The data on foliar stage at root emergence given as part of table $V$ and fig 3 are only indicative.

The number and diameter of adventicious roots vary (increase) from one whorl to the other and this can be used to identify the rank of nodes and leaves as suggested by Picard et al (1985). Diameter of roots (measured at about $1 \mathrm{~cm}$ from their attachment to the stem) are given in table V. If thick roots are defined as roots with a diameter $\geq 4-5 \mathrm{~mm}$ then the first (starting from stem base) whorl of thick roots correspond to node 4 . Roots of node 0 (coleoptilar node) to 2 are thin, from node $0-2$ the diameter increases from a value of about $1 \mathrm{~mm}$ to about $3 \mathrm{~mm}$. Root diameter may be visually estimated by comparison with the rhizome (mesocotyl) which displays a diameter of 2-3 mm. Lowermost nodes rarely develop more than 4 roots each. The first node to display a clearly higher number of primary adventicious roots is node 4 (with about 6 roots, exp 3, table $\mathrm{V})$, but this is not general (table $V$, exp 2). Node 5 bears about 9 roots whereas node 6 (above soil level), bears about 12 roots or root primordia (table V). These numbers are likely to vary widely with genotypes and environmental conditions (Varlet-Granger et al, 1987; Jordan et al, 1988), although they are comparable to those presented by Picard et al (1985). In 1989 a warmer and dryer year than normal, the number of roots tented to be higher $(\exp 6$, table $V)$ in node 4 and to a lesser extent in node 5 (no observations were made on lower nodes).

In $\exp 7$, also, observations were only made on node 4 and 5 . The number of roots for those 2 nodes respectively was: $7.2 \pm 1.80$ and $11.4 \pm 2.36 \quad$ (Dea, $n=16), \quad 9.0 \pm 1.32$ and $11.0 \pm 1.47$ (Gracia, $n=10$ ), $8.0 \pm 1.28$ and $10.3 \pm 1.64$ (Lixis, $n=18$ ); roots at node 6 on the contrary generally did not develop (exp 6 and 7$)$.

Root whorls at nodes 2 and 3 are difficult to distinguish from one another on a fully developed

Table IV. Distance (cm) between stem tip (coleoptilar node) and nodes of leaves 3 to 6 .

(a) mean and standard deviation; $\exp 2, n=5$; (b) range of values observed; $\exp 1$ and $3 n=25$; (c) $\exp 6 n=19$; not measured.
Brulouis
Dea
Tonus
Lixis
Lixis
(a)
(b)
(c)

\begin{tabular}{lllllllll}
\hline 6 & $4.2(0.30)$ & $3.9(0.49)$ & 4.6 & $(0.86)$ & $4.1-7.9$ & $7.8(2.14)$ \\
5 & $2.4(0.13)$ & $2.5(0.22)$ & 2.5 & $(0.22)$ & $2.3-3.1$ & $3.2(0.37)$ \\
4 & $1.4(0.10)$ & $1.6(0.11)$ & 1.6 & $(0.11)$ & $1.3-1.7$ & $1.6(0.14)$ \\
3 & $0.8(0.15)$ & $1.0(0.09)$ & $1.0(0.09)$ & $0.7-1.0$ & - & - \\
\hline
\end{tabular}


Table V. Roots emerging from lower nodes: number, diameter, time of emergence.

(a) First number is mean, number in parentheses is standard deviation $(n=5)$, exp 2 or $n=20$ exp 6; (b) Range of values observed in exp 1 and 3; number of roots in nodes 2 and 3 are particularly difficult to determine: 4-7 roots are found in nodes 3+2. Sign - means that determination was not done; (c) Measured at $1 \mathrm{~cm}$ from root attachment, with a calliper; range of values in exp 1 and $3(n=15)$ means are in parentheses, CV 7 to 14\%; (d) Node 0 is coleoptilar node. Measurements are either destructive (for nodes below soil level, 0 to 4 ) or non-destructive (nodes at or above soil level: node 5, in many cases, and node 6).

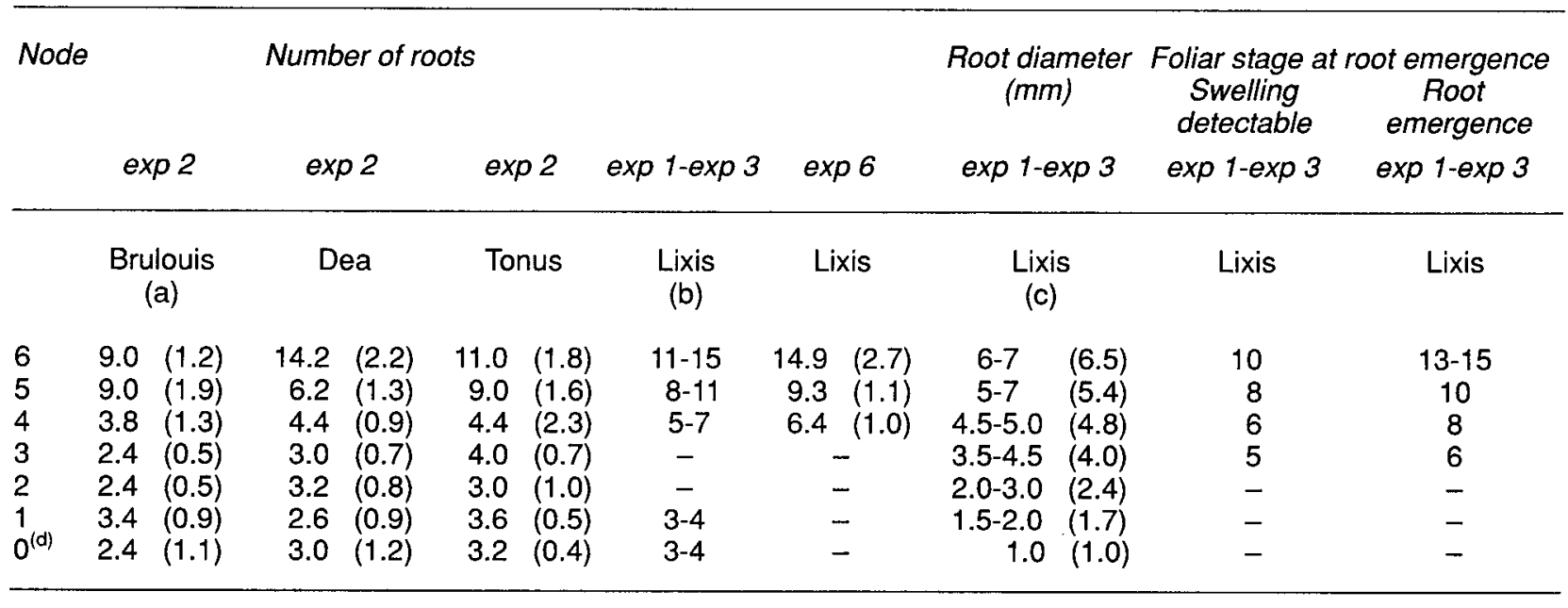

stem basis. Roots of node 0 and 1, however are easily observed: seen from below, the pyramid tip forms a star with 6-8 branches formed by 2 whorls of about 3-4 thin roots each (fig 3). This number of roots corresponds to observations by Varlet-Granger et al, 1987, for Dea.

\section{Assessing the accuracy and practicability of the different methods}

The criteria were basically determined on experiments conducted in 1987 and 1988. The observations made in 1989 (exp 6 and 7) were basically for testing the technique on data different from those used for developing it. Sixty plants (exp 6, Lixis) or 20 plants exp 7, Dea, Gracia, Lixis) were labelled per variety and rank of successive leaves were noted as soon as they emerged. Markings were made later on leaves 5 or 7 . The technique was explained to 3 different individuals ( $\mathrm{N}^{\circ} 1$ to 3 ) who had not participated to the work in ' 87 and ' 88 . Two of them had no previous experience with maize. The determination was made directly in the field on the base of visual estimations. $A$ fourth determination was made by 1 individual $\left(N^{\circ} 4\right)$ who had participated in the previous year's experiment and in his case, the determination was made in the laboratory on the basis of numerical data collected in the field by the other individuals. Two individuals $\left(\mathrm{N}^{\circ} 1\right.$ and 4) succeeded in making a perfect score. Others made usually $80 \%$ or more correct determinations.
Method 6 (based on the number of roots) and to a lesser extent method 4 (based on internode length) gave poorer results (table VI). Combination of several methods gives the best results (perfect score). A personal estimation of applicability, and reliability of the different methods is given in table VII. Scoring by experienced individuals with the more appropriate method or combination of methods according to table VII (corresponding to ++ in table VII) gives more than $90 \%$ correct determinations. Experience in using the criteria facilitates leaf identification.

Criteria should be used as patterns allowing to discriminate between different possible leaf identification. They should not be applied strictly or blindly. For instance, the sequence of internode lengths $3,1.3,1.3,1$ or $2.0,1.5,1.3,1$ allows unambiguous identification of leaf rank although 1 element (underlined) does not strictly follow the model $2^{+}, 2^{-} 1.5,1$. On the contrary, the sequence $1.9,1.5,1.3,1$ for internode relative length is ambiguous. The same applies to the height of collars $\left(h_{c}\right)$ of leaves 5 and 6 . The sequence $8,12,19$, or $7,9.5,20$ are unambiguous whereas the sequence $7,9.5,14$ is since both 9.5 and 14 could apply to leaf 5 .

\section{CONCLUSION}

Accurate determination of foliar stage is possible throughout the season, even when the lower leaves have completely disappeared. As season and development progress, the number of 
Table VI. Percentage of correct determinations of leaf rank, using different methods.

a) 1. first leaf lamina length is $\pm 5 \mathrm{~cm} ; 2$. collar of leaf $5 \geq 10 \mathrm{~cm}$ and collar of leaf $6>15 \mathrm{~cm}$ above soil level, collar of leaf $4<10 \mathrm{~cm}$; 3 . node 5 is first node visible at or above soil level. Its length relative to soil level is $\leq 2 \mathrm{~cm} ; 4$. lower aerial internodes are in the proportion $2^{+}, 2^{-}, 1.5^{-}, 1$ (upwards ie $2.5,1.5,1.3,1 ; 5$. distance of whorls 4 and 5 , of adventicious roots is 1.5 and $2.5-3 \mathrm{~cm}$ from shoot tip; 6 . number of adventicious roots on whorls 4 and 5 are about 6 and 9 ; b) 1 number of fully emerged leaves, d number of days after silking, do dough stage of grain; c) for Lixis, Gracia, Dea respectively.

\begin{tabular}{|c|c|c|c|c|c|c|}
\hline Method & Date & Stage & $\exp$ & $n$ & Observer & \% Success \\
\hline $1^{\text {a) }}$ & $22 / 6$ & $81^{b}$ & 6 & 20 & 1 & 100 \\
\hline \multirow[t]{3}{*}{2} & $24 / 7$ & $4 d^{b}$ & 6 & 52 & 4 & 90 \\
\hline & $2 / 8$ & $13 d$ & 7 & 20 & 3 & $65,80,90$ \\
\hline & $2 / 8$ & $13 d$ & 7 & 20 & 4 & $90,80,80^{\circ}$ \\
\hline \multirow[t]{3}{*}{3} & $24 / 7$ & $4 d$ & 6 & 52 & 4 & 98 \\
\hline & $2 / 8$ & $13 d$ & 7 & 20 & 3 & $75,80,90^{\circ}$ \\
\hline & $2 / 8$ & $13 d$ & 7 & 20 & 4 & $80,100,90^{\circ}$ \\
\hline \multirow[t]{2}{*}{4} & $2 / 8$ & $13 d$ & 7 & 20 & 3 & $-, 70,75^{c}$ \\
\hline & $2 / 8$ & $13 d$ & 7 & 20 & 4 & $85,60,70^{c}$ \\
\hline 5 & $11 / 9$ & $\mathrm{do}^{\mathrm{b}}$ & 7 & 20 & 4 & $90,95,85^{\circ}$ \\
\hline 6 & $11 / 9$ & do & 7 & 20 & 4 & $55,40,70^{\circ}$ \\
\hline \multirow[t]{3}{*}{$2+3$} & $22 / 6$ & 81 & 6 & 40 & 1 & 100 \\
\hline & $24 / 7$ & $4 d$ & 6 & 52 & 4 & 100 \\
\hline & $2 / 8$ & $13 d$ & 7 & 20 & 4 & $100,95,95^{\mathrm{c}}$ \\
\hline \multirow[t]{2}{*}{$3+4$} & $25 / 7$ & $8 d$ & 6 & 51 & 2 & 85 \\
\hline & $28 / 7$ & $8 d$ & 6 & 40 & 1 & 100 \\
\hline
\end{tabular}

Table VII. Scoring the different methods for reliability and practicability.

(a) not usable,;,,-+++ , indicate increasing levels of reliability (decreasing risk of error in determining leaf rank); (b) relative to soil level; (c) depending on the progress of senescence; in conditions where development of aerial roots is limited, or (and) under dry conditions (no decomposition of completely senescent leaves), the position of collars can still be determined on the dried leaves, in early September; (d) destructive.

Method-criteria used

$$
4^{\text {Foliar stage }}
$$

12

16

or least leaf

15 days after silking and later

1. Direct determination of leaf 1

2. Position ${ }^{b}$ of collars of leaves $5-6$

3. Position ${ }^{b}$ of node 5

4. Sequence of internode lengths

5. Distance of nodes 4-5 to stem tip ${ }^{d}$

6. Number of adventicious roots on nodes ${ }^{d}$

$\begin{array}{ccc}++^{\mathrm{a}} & - & 1 \\ / & ++ & ++ \\ 1 & - & + \\ 1 & 1 & - \\ 1 & - & ++ \\ - & - & -,+\end{array}$

$/$
+ to $/$,
+ to ++
+
++
-+

\section{I}

+ to $f$

+ to ++

$+$

$++$

$-,+$ methods available increase. They all allow direct or indirect, identification of leaf (or node) 5 and, from there, identification of all remaining leaves. For correct determination of foliar stage, it always remains advisable to use more than 1 single method. Both non-destructive and destructive methods are available. Results might apply only to healthy plants growing in the field under the usual cropping techniques in use in NorthWestern Europe. Moreover, the criteria presented were tested only on a subset of cultivars with FAO number $<300$, as used in Belgium and Northern Europe. Adaptation of the criteria presented is likely to be necessary for other types of varieties or climate. Nevertheless, the principles of the method should be adaptable in all situations.

Independently of the problem of leaf identification, a study of environmental effects of the criteria presented might prove useful for understanding yield variations. Stress in abnormal conditions at given stages of development could indeed affect quantitatively plant morphology described by the various criteria presented for leaf determination. A study of these deviations could shed light on the problems 
encountered during plant development. Observation of relationships between morphological characters has been suggested as a method for obtaining information on the preceding growth condition, and therefore on yield variations (Ledent, 1984).

\section{ACKNOWLEDGMENT}

The authors thank O Cappellen, G Leclerc, A Pauwels, A Kin, $F$ Goor and $N$ Albade for their participation in the work at various stages of this research.

\section{REFERENCES}

Anonymous (1981a) Échelle de notation des stades du maïs. Document réalisé par le service technique de I'AGPM et la station d'agronomie de I'INRA de Colmar, 4

Anonymous (1981b) Stades repères du maïs. Gavadour Cargill. Agromais 1, 33

Barloy J (1984) Phase germination, levée et implantation. Physiologie du maïs. Communication au Colloque Physiologie du maïs. Royan 15-17 mars 1983. (Gallais A, ed) INRA, Paris 13-48

Bonhomme R (1984) Mise en place des appareils foliaire et racinaire. Physiologie du maïs. Communication au Colloque Physiologie du maïs. Royan 15-17 mars 1983. (Gallais A, ed) INRA, Paris 63-85

Delhaye RJ (1985) Phénologie des diverses plantes de grande culture en Belgique. Revue de I'Agriculture 38, 1377-1408

Gay JP (1984) Le cycle du maïs. Physiologie du maïs. Communication au Colloque Physiologie du maïs. Royan 15-17 mars 1983. (Gallais A, ed) INRA, Paris $1-11$

Gay JP (1985) Stades phénologiques du maïs. Agromais 36, 14-15

Gay JP, Menetrier MA (1978) Morphogenèse des organes reproducteurs chez le maïs. Echelle de notation des stades. AGPM, ITCF, Pau, Paris

Girardin Ph, Jordan MO, Picard D, Trendel R (1986) Harmonisation des notations concernant la description morphologique d'un pied de maïs. (Zea mays L). Agronomie 6, 873-875

Groot JJR, Kropff MJ, Vossen FJH, Spitters CJT, Rabbinge $R$ (1986) A decimal code for the developmental stages of maize and its relation to accumulated heat units. Netherlands Journal of Agricultural Science 34, 67-73
Hanway JJ (1963) Growth stages of corn (Zea mays L). Agron J 55, 487-492

Hanway JJ (1966) How a corn plant develops. Special report $n^{\circ} 48$. lowa State Univ, Cooperative Ext Service

Jones CA, Kiniry JR (1986) Ceres-Maize. A simulation model of maize growth and development. Texas $A$ and $M$ University Press, College Station

Jordan MO, Girardin PH, Varlet-Granger C, Picard D, Trendel R (1988) Rythme d'apparition des racines primaires du maïs (Zea mays L) III. Variations observées au champ. Agronomie 8, 37-46

Kiniry JR, Ritchie JT (1981) Rates of leaf primordia and tip appearance of different maize genotypes in the field. Agron Abstr, American Society of Agronomy 12

Kiniry JR, Ritchie JT, Musser RL (1983a) Dynamic nature of the photoperiod response in maize. Agron J 75, 700-703

Kiniry JR, Ritchie JT, Musser RL, Flint EP, Iwig WC (1983b) The photoperiod sensitive interval in maize. Agron J 75, 687-690

Ledent JF (1984) Morphological characters: a physiological analysis. Efficiency in Plant Breeding (Lange W, Zeven AC, Hogenboom NG, eds) Pudoc, Wageningen 65-68

Ledent JF (1988) Foliar stages in maize, adaptation of Haun's scale. Proc of 14th Congress of the maize and sorghum section of Eucarpia. Nitra, Czechoslovakia, 7-11 Sept 1987 (Hùska J, Janda J, Nesticky M eds)

Picard D, Jordan MO, Trendel R (1985) Rythme d'apparition des racines primaires du maïs (Zea mays $L$ ). I. Etude détaillée pour une variété en un lieu donné. Agronomie 5, 667-676

Schütte $F$, Meier U (1981) Entwicklungsstadien des Maïs, Biol Bundesanstalt (BBA) für Land und Forstwirtschaft, Braunschweig. Merkblatt 2714, 10

Sibma $L$ (1987) Ontwikkeling en groei van maïs, Zea mays, onder Nederlandse omstandigheden Pudoc (Gewassenreeks $\mathrm{nr}$ 1), Wageningen

Stapper M, Arkin GF (1980) CORNF: A dynamic growth and development model for maize. Doc $n^{\circ}$ 80-2, Texas Agric Exp Sta Temple

Tollenaar M, Daynard TB, Hunter RB (1979) Effect of temperature on rate of leaf appearance and flowering date in maize. Crop Sci 19, 363-366

Tollenaar M, Hunter RB (1983) A photoperiod and temperature sensitive period for leaf number of maize. Crop Sci 23, 457-461

Varlet-Granger C, Derieux M, Jordan MO, Girardin PH, Picard D (1987) Rythme d'apparition des racines primaires du maïs (Zea mays L) II. Variations observées sur quelques génotypes. Agronomie 7, 695-702 